\title{
Chemical Compounds and Pharmacological Activities of Cucumis genus
}

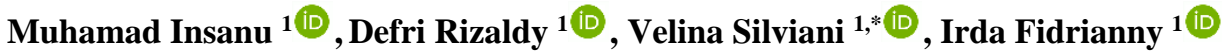 \\ 1 Department of Pharmaceutical Biology, School of Pharmacy, Bandung Institute of Technology, Bandung, Indonesia; \\ muhamad.insanu@gmail.com (M.I.); defri.rizaldy@gmail.com (D.R.); $\quad$ silvianivelina@gmail.com (V.S.); \\ irdafidrianny@gmail.com (I.F.); \\ * Correspondence: silvianivelina@gmail.com;
}

Received: 10.03.2021; Revised: 10.04.2021; Accepted: 14.04.2021; Published: 27.04.2021

\begin{abstract}
Cucumis genus is one of the genera from the Cucurbitaceae family. Cucumis genus plants have many health benefits. They are known as traditional medicinal plants in several countries in Asia, including Indonesia. This literature review discusses the topic of traditional use, phytochemical compounds, nutritional content, pharmacological activity, genotoxicology, and toxicity tests of the Cucumis genus plants based on data obtained from scientific databases and search engines such as PubMed, Scopus, Science Direct, and Google Scholar. Cucumis genus plants contain many chemical compounds, such as cucurbitacin, phenolic compounds, vitamins, minerals, essential oils, and fatty acids. Several studies have shown that Cucumis genus plants exhibited some pharmacological activities such as antimicrobial, analgesic, antioxidant, anti-inflammatory, antidiabetic, antiwrinkle, and anticancer activity. Cucumis genus plants also have useful therapeutic effects for osteoarthritis, ulcerative colitis, and wound healing. Each part of Cucumis genus plants contains phytochemical compounds that are different from one another. Their pharmacological activities are also different, depending on the phytochemical compounds and Cucumis genus plants' plant parts. However, more recent studies are needed regarding the genotoxicology and toxicity of the Cucumis genus plants.
\end{abstract}

Keywords: Cucumis genus; chemical compounds; pharmacological activities.

(C) 2021 by the authors. This article is an open-access article distributed under the terms and conditions of the Creative Commons Attribution (CC BY) license (https://creativecommons.org/licenses/by/4.0/).

\section{Introduction}

The Cucurbitaceae family consists of 130 genera and 800 species [1]. Cucurbitaceae has long been known as a traditional medicine in several countries in Asia, including Indonesia because Cucurbitaceae contained protein and antioxidants. Cucurbitaceae fruits were known to be low in fat and calories, so people often consumed them as food [2]. Many researchers had developed Cucurbitaceae plants to be used as cosmetics and skincare for skin problems such as wrinkles and aging [3]. One of the popular genera from the Cucurbitaceae family is Cucumis. There are 25 species of Cucumis in Asia. Cucumis plants that people mostly consume are cucumber (Cucumis sativus) and melon (Cucumis melo). C. sativus and C. melo have many wild relatives in Asia and Australia [4]. Their tap and fibrous roots characterize Cucumis plants. The stems of Cucumis plants are green, wet, and watery, but they are strong. The stems are segmented, and they have fine hair. Cucumis plants are creepers. They have broad leaves that grow alternately. Chemical compounds contained in several Cucumis plants and their pharmacological activities will be explained in this review. 


\section{Materials and Methods}

Data in this review were based on data obtained from scientific databases and search engines such as PubMed, Scopus, Science Direct, and Google Scholar. The search was performed using the keywords Cucumis, pharmacological activities, and chemical compound. Source articles were published for a maximum of 10 years, with a minimum of 20 articles in the last 2 years. Each source article has a DOI number. This literature review was done by reviewing 57 articles. Each source article was checked for quality by checking each journal index. Scopus indexed the articles used in this review. They were checked on the scopus.com website.

\section{Results and Discussion}

\subsection{Chemical compounds.}

Plants produce many secondary metabolites. They can be used for medicine [5]. $C$. sativus fruit contained phytochemical compounds such as carbohydrates, flavonoids, glycosides, and steroids [6]. C. sativus fruit was made up of $95 \%$ water and contained lots of vitamin A and C. Phytochemical screening of the ethanol extract of the leaf and stem of $C$. sativus showed the presence of alkaloids, glycosides, steroids, saponins, and tannins. The chloroform extract of the leaf and stem of $C$. sativus contained alkaloids, glycosides, steroids, flavonoids, saponins, and tannins. In C. sativus leaves, there were also flavone glycosides such as isovitexin, saponarin, and acylated C-glycosides [7]. Ethanol extract of $C$. sativus leaves contained alkaloids, glycosides, steroids, flavonoids, saponins, and tannins. The acetone extract of $C$. sativus leaves also contained flavonoids [8]. C. melo contained polyphenols such as flavonoids and tannins [9]. Besides that, $C$. melo also contained sterols, saponins, and amino acids [10]. C. melo seeds had phenolic glycosides [7]. Alkaloids, flavonoids, tannins, steroids, saponins, glycosides, and phenols were distributed in the peel of Cucumis metuliferus [11].

\subsubsection{Cucurbitacin.}

Cucurbitacins are triterpenoid compounds with various structures. Cucurbitacin is an oxygenated tetracyclic triterpene that can be found in many Cucurbitaceae plants, including in Cucumis genus [12]. Researchers have widely studied cucurbitacin because of its pharmacological potentials [5]. Cucumis fruits and roots have a high cucurbitacin content, while Cucumis seeds have a low cucurbitacin content [13]. Based on the structure, Cucurbitacin compounds are divided into 17, Cucurbitacin A, B, C, D, E, F, G, H, I, J, K, L, O, P, Q, R, and $\mathrm{S}$ [13]. The structures of a few cucurbitacins (A, B, C, D, E, and I) were given in Figure 1. $C$. sativus contained Cucurbitacin A, B, C, D, E, and I. Cucurbitacin C in C. sativus caused a bitter taste $[14,15]$. Cucurbitacin $\mathrm{E}$ had high toxicity properties because its hydrophobicity was the highest compared to other cucurbitacins [5]. Cucurbitacin E could inhibit cell adhesion [16].

Cucurbitacin B, D, E, I, and L were also accumulated in C. melo [17,18]. C. melo had a high amount of Cucurbitacin B, D, E, and 2-O- $\beta$-D-glucopyranosyl cucurbitacin B [10]. Cucurbitacin B from $C$. melo was commonly used as liver protection medicine in curing hepatic lesions and liver cancer [18]. Cucurbitacin extract from C. melo fruit has the ability to reduce systolic blood pressure (SBP) by improving blood vessel tension [10]. 

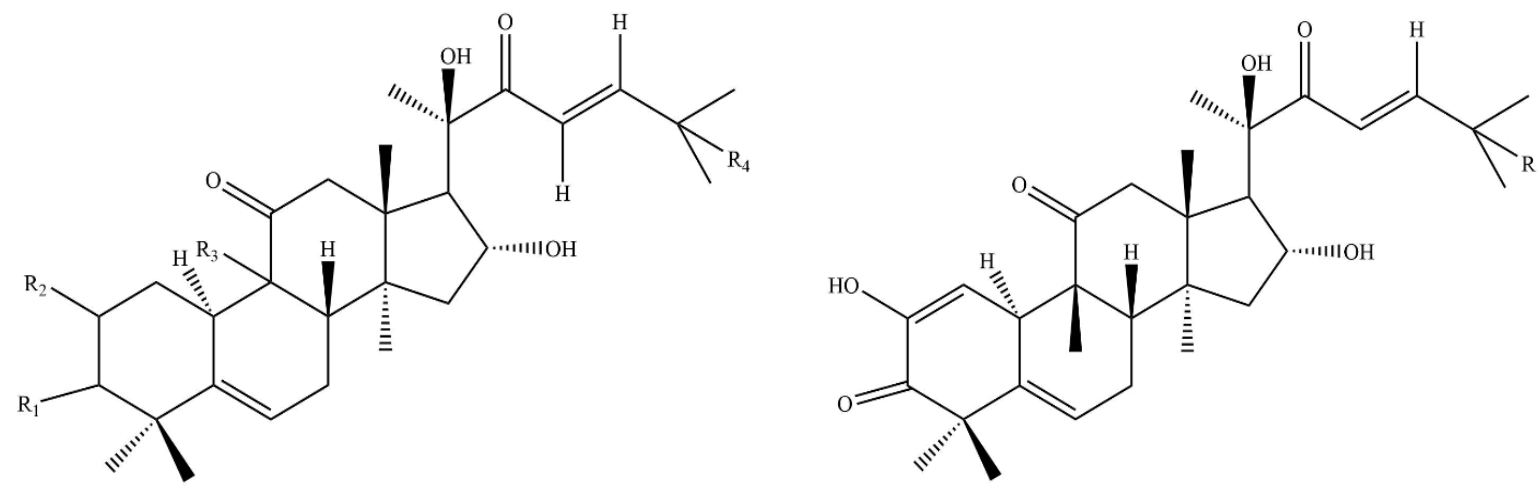
(1) $\mathrm{R}_{1}==\mathrm{O}$
$\mathrm{R}_{2}=-\mathrm{OH}$
$\mathrm{R}_{3}=-\mathrm{CH}_{2} \mathrm{OH}$
(5) $\mathrm{R}=-\mathrm{OC} \mathrm{OC} \mathrm{H}_{3}$
(2) $\mathrm{R}_{1}==\mathrm{O}$
$\mathrm{R}_{2}=-\mathrm{OH}$
$\mathrm{R}_{3}=-\mathrm{H}$
(6) $\mathrm{R}=-\mathrm{OH}$
(3) $\mathrm{R}_{1}=-\mathrm{OH}$
$\mathrm{R}_{2}=-\mathrm{H}$
$\mathrm{R}_{3}=-\mathrm{CH}_{2} \mathrm{OH}$
(4) $\mathrm{R}_{1}==\mathrm{O}$
$\mathrm{R}_{2}=-\mathrm{OH}$
$\mathrm{R}_{3}=-\mathrm{H}$

Figure 1. Structure of Cucurbitacin A (1), Cucurbitacin B (2), Cucurbitacin C (3), Cucurbitacin D (4), Cucurbitacin E (5), and Cucurbitacin I (6).

Cucurbitacin B, D, E, I, IIa, L glucoside, Q, dan R were the most active cucurbitacin components against cancer through inhibition of migration and invasion, proapoptosis, and cell cycle arrest promotion [19].

\subsubsection{Phenolic compounds.}

Phenolic compounds are secondary metabolites that are widely found in plants. Most of the phenolic compounds are flavonoids and phenolic acid. Phenolic compounds had antioxidant activity potential, so they are commonly used for disease prevention [20]. Based on research, there were 73 phenolic compounds identified in $C$. sativus. The identification was made by the mass spectrometry (MS) method. Phenolic compounds that were identified in $C$. sativus using this method such as quercetin 3-L-rhamnoside, naringenin 7-O- $\beta$-D-glucoside, kaempferol-3,7-O- $\alpha$-L-dirhamnoside, apigenin 7-rutinoside, kaempferol 3-O-sambubioside, vicenin 2, diosmetin-apiosylglucoside, theaflavanosidel, luteolin-6-C-(6-malonyl)hexoside-8C-pentoside, laricresinol 9-O- $\beta$-D-glucopyranoside, luteolin 7-O-glucuronide, and isorhamnetol 3-O-rutinoside. Through this research, it can be stated that $C$. sativus is a good source of phenolic compounds [21].

C. melo seeds, leaves, flesh, peels, and stems were also contained phenolic compounds. Flavonoids were the main phenolic compounds in C. melo. C. melo was also a good source of phenolic compounds [22]. C. melo leaf extract showed the highest total phenolic content compared to other plant parts $(26.4 \pm 0.3 \mathrm{mg} \mathrm{GAE} / \mathrm{g}$ extract) and total flavonoid content (69.7 $\pm 3.37 \mu \mathrm{g} \mathrm{RE} / \mathrm{g}$ extract). This research also revealed that $C$. melo leaf and stem extract figured the best antioxidant activity compared to other plant parts [23].

C. melo peels were identified using the High-Pressure Liquid Chromatography (HPLC) method. The result showed that 3-hydroxybenzoic acid and flavones were their main phenolic compounds. The total 3-hydroxybenzoic acid content in $C$. melo peels was $33.45 \mathrm{mg} / 100 \mathrm{~g}$. Besides that, apigenin-7-glycosides were also found $29.34 \mathrm{mg} / 100 \mathrm{~g}$ [24].

These were other phenolic compounds that were also identified in C. melo: gallic acid, hydroxytyrosol, protocatechuic acid, tyrosol, chlorogenic acid, 4-hydroxybenzoic acid, isovanillic acid, luteolin-7-glycoside, naringenin, oleuropein, m-cumaric acid, phenylacetic 
acid, luteolin, pinoresinol, and amentoflavone [24-26]. The structures of few phenolic compounds identified in $C$. melo peels were displayed in Figure 2.<smiles>O=C(O)c1cc(O)c(O)c(O)c1</smiles>

Gallic acid<smiles>O=C(O)c1ccc(O)c(O)c1</smiles>

Hydroxytyrosol

Procatechuic acid<smiles>OCCc1ccc(O)cc1</smiles><smiles>O=C(/C=C/c1ccc(O)c(O)c1)O[C@@H]1C[C@@](O)(C(=O)O)C[C@H](O)[C@H]1O</smiles><smiles>O=COc1ccc(C(=O)O)cc1O</smiles><smiles>O=C(O)c1cccc(O)c1</smiles><smiles>O=C(O)c1ccc(O)cc1</smiles><smiles>O=C1CC(c2ccc(O)c(O)c2)Oc2cc(O)cc(O)c21</smiles>

Luteolin

4-Hydroxybenzoic acid<smiles>O=c1cc(-c2ccccc2)oc2ccccc12</smiles>

Flavone<smiles>O=C(O)/C=C/c1cccc(O)c1</smiles>

$m$-Cumaric acid

Figure 2. Structure of phenolic compounds identified in C. melo peels.

\subsubsection{Vitamin and minerals.}

The result of vitamin analysis, exposed that methanol leaf extract of $C$. sativus contained a high amount of vitamin A $(23.00 \pm 0.01 \mathrm{mg} / \mathrm{kg})$, vitamin B1 $(0.03 \pm 0.01 \mathrm{mg} / \mathrm{kg})$, vitamin B2 $(0.03 \pm 0.02 \mathrm{mg} / \mathrm{kg})$, vitamin B6 $(0.44 \pm 0.01 \mathrm{mg} / \mathrm{kg})$, vitamin C $(6.11 \pm 0.02$ $\mathrm{mg} / \mathrm{kg})$, vitamin $\mathrm{E}(0.09 \pm 0.01 \mathrm{mg} / \mathrm{kg})$, niacin $(0.41 \pm 0.01 \mathrm{mg} / \mathrm{kg})$, and folate $(15.00 \pm 0.02$ $\mathrm{mg} / \mathrm{kg}$ ) [27]. Rind and pulp of cucumber fruit contained high amount of vitamin $\mathrm{C}$ and vitamin $\mathrm{B} 1$ [28]. C. sativus rind and pulp contained mineral elements such as $\mathrm{K}, \mathrm{Ca}, \mathrm{Mg}, \mathrm{Zn}, \mathrm{Fe}, \mathrm{Mn}$, $\mathrm{Na}$ and $\mathrm{Cu}[29]$.

Another research showed that the rind of Cucumis metuliferus was rich in vitamins $\mathrm{C}$, $\mathrm{E}, \mathrm{D}, \mathrm{B} 9$, and $\mathrm{A}$ with a high content of vitamins $\mathrm{B} 2, \mathrm{~K}, \mathrm{~B} 1$, and $\beta$-carotene [11]. C. melo contained nutrients like vitamins and minerals [30]. C. melo was a good source of vitamin $\mathrm{C}$ and A [31]. C. melo contained minerals elements such as N, P, Ca, Mg, Fe, and $\mathrm{Na}$ [32]. 


\subsubsection{Essential oils and fatty acids.}

Essential oils are volatile liquids that can widely found in plants. C. melo seed oil was rich in essential oil. It contained $\alpha$-spinasterol, stigmasta-7,22,25- trienol and stigmasta-7,25dienol. They have phenol groups [33]. C. melo seed oil also contained some major fatty acids such as linoleic acid (4.6\%), oleic acid (21.12\%), palmitic acid (17.68\%), and stearic acid $(10.84 \%)$ [34].

C. sativus was a good source of essential oil. Chemical compounds of the essential oil of $C$. sativus fruits were 3-nonenal, nonanal, E,Z-2,6-nonadienal, Z-3-nonenol, E-2-nonenal, Z-6-nonenol, n-decanal, E,E-2,4-nonadienal, E,E-2,4 decadienal, E,Z-2,4-decadienal, E- $\beta$ damascenone, 1 -tetradecene, tetradecane, $\alpha$-humulene, $\beta$-ionone, tridecanal, caryophyllene oxide, tetradecanal, pentadecanal, 9,12,15-octadecatrienal, and 9,17,octadecadienal [35].

\subsection{Pharmacological activities.}

\subsubsection{Antimicrobial activity.}

C. sativus fruit extracts were analyzed for their antimicrobial activity against six Gramnegative and Gram-positive strains (Staphylococcus aureus, Staphylococcus epidermidis, Pseudomonas aeruginosa, Enterobacter cloacae, Klebsiella pneumoniae, and Escherichia coli). The tested extracts were dichloromethane peel extract, methanol peel extract, dichloromethane pulp extract, and methanol pulp extract. The result showed that $C$. sativus fruit extracts have a strong antibacterial activity, especially the dichloromethane and methanol pulp extract (MIC $2.43-3.15 \mathrm{mg} / \mathrm{ml}$ ) [35].

Sphingolipids were isolated and identified from $C$. sativus stems. These sphingolipids exposed vigorous antifungal activity on Pythium aphanidermatum and Botrytis cinerea. These sphingolipids also exhibited potent antibacterial activity on Bacillus subtilis, Xanthomonas vesicatoria, and Pseudomonas lachrymans [36]. C. sativus seed extract also had significant potential as an antimicrobial agent, especially on E. coli strains [37].

Cucumis anguria leaf extract was tested for its potential as an antibacterial agent. The result revealed that $C$. anguria leaf extract could be used to synthesize silver nanoparticles, making C. anguria leaf extract a good source of antibacterial agent, especially for $S$. aureus and E. coli [38].

C. melo had good antifungal activity. Vicilin-like proteins isolated from C. melo expressed potent antifungal activity against pathogenic fungal species such as Fusarium oxysporum [7]. C. melo methanolic and ethanolic leaf and seed extract gave antibacterial activity against $S$. aureus and other Gram-positive strains [39,40]. C. melo fruit had been traditionally used as an antiparasitic agent because of its anthelmintic and vermifuge activity [41].

\subsubsection{Antioxidant activity.}

C. sativus fruit was tested by 2,2-diphenyl-1-picrylhydrazyl (DPPH) method and superoxide radical scavenging assay, which used butylated hydroxytoluene as standard for its antioxidant activity. C. sativus fruit extract exhibited significant DPPH free radical and superoxide radical scavenging activity with $\mathrm{IC}_{50}$ at $14.73 \pm 1.42$ and $35.29 \pm 1.30 \mu \mathrm{g} / \mathrm{ml}$, compared to butylated hydroxytoluene $\mathrm{IC}_{50}$ at $31.38 \pm 1.43$ and $51.79 \pm 1.05 \mu \mathrm{g} / \mathrm{ml}$ [43]. 
Nonphenolic compounds such as uracil and 24-methylenecycloartenol in C. sativus fruit expressed a high antioxidant activity [35].

High content polyphenols and carotenoids in $C$. melo displayed a high antioxidant activity. C. melo leaf, peel, pulp, and seed extracts were examined by the DPPH method for their antioxidant activity. The results stated that they had antioxidant activity. The IC 50 value of $C$. melo leaf methanolic extract was $780,1 \mu \mathrm{g} / \mathrm{ml}, C$. melo lyophilized peel methanolic extract was $189.02 \mu \mathrm{g} / \mathrm{ml}$, C. melo oven-dried peel methanolic extract was $370.93 \mu \mathrm{g} / \mathrm{ml}$, C. melo pulp n-hexane extract was $335 \mu \mathrm{g} / \mathrm{ml}$, and $C$. melo seed methanolic extract was $653.57 \mu \mathrm{g} / \mathrm{ml}[26$, 43-45].

\subsubsection{Anti-inflammatory activity.}

The methanolic extract of $C$. sativus leaves was identified for its anti-inflammatory activity in the Long Evans rat model at two doses (150 and $250 \mathrm{mg} / \mathrm{kg} \mathrm{bw}$ ). The effects were compared to indomethacin $(10 \mathrm{mg} / \mathrm{kg} \mathrm{bw})$ as standard. The result showed that $C$. sativus leaves extract could significantly reduce inflammation by $57.35 \%(150 \mathrm{mg} / \mathrm{kg} \mathrm{bw})$ and $72.06 \%$ (250 $\mathrm{mg} / \mathrm{kg} \mathrm{bw})$ compared to the standard drug (79.41\%) [46].

Other research also showed that $C$. sativus extract could attenuate lipopolysaccharide (LPS)-induced inflammatory response in endothelial cells [47]. C. sativus aqueous fraction also could reduce Angiotensin II-induced inflammatory factors [48]. Iminosugar idoBR1 (an iminosugar amino acid isolated from $C$. sativus fruit) could work as an anti-inflammatory agent by inhibiting sialidase in the production of functionally active HA adhesive CD44 [49].

C. melo was also known for its anti-inflammatory activity. C. melo fruit extract had a high Superoxide Dismutase Activity (SOD). SOD was responsible for anti-inflammatory activity in C. melo [50].

\subsubsection{Anticancer activity.}

C. sativus fruit methanol and acetone extracts were evaluated for their anticancer activity. The results reported that $C$. sativus fruit was rich in bioactive compounds which have anticancer activity with cell lines of $\mathrm{IC}_{50}$ (MCF 715.6 \pm 1.3 and HeLa 28.2 \pm 1 ) [8].

Cucurbitacins in $C$. sativus worked as an anticancer agent through some mechanisms of action by inhibiting cell proliferation, preventing migration and invasion, promoting apoptosis, and promoting cell cycle arrest. Cucurbitacins also inhibited some signaling pathways included JAK-STAT3 (Janus Kinase-Signal Transducer and Activator of Transcription Proteins 3), Wnt, PI3K/Akt (Phosphatidylinositol 3-Kinase/Protein Kinase B), and MAPK (Mitogen-Activated Protein Kinase) pathway. Those signaling pathways play important roles in cancer cells' apoptosis and survival. Synergistic anticancer effects using cucurbitacins together with chemotherapeutic drugs (such as methotrexate and docetaxel) had been discovered and used to treat cancer [19].

Cucumis prophetarum also demonstrated anticancer activities against six cancer cell lines, such as human breast cancer cell (MCF7, MDA-MB-231), colon cancer cell (HCT-116), ovarian cancer cell (A2780/A2780CP), and liver cancer cell (HepG2). Cucurbitacin compounds were responsible for their anticancer activity. Cucurbitacin E and Cucurbitacin B showed the best effect against cancer cells [51].

3.2.5. Antidiabetic activity. 
Ethanolic extract of $C$. sativus peels was tested at 250 and $500 \mathrm{mg} / \mathrm{kg}$ dose for 15 days in the alterations in serum glucose and hepatic lipid peroxidation (LPO) in male mice. The result showed that ethanolic extract of $C$. sativus peels had the potential to regulate alloxan induces diabetes mellitus and associated changes in serum lipids and thyroid hormones. The better effects were tested at $500 \mathrm{mg} / \mathrm{kg}$ dose [52].

Cucumis trigonus fruit aqueous extract was evaluated for its antidiabetic activity in streptozotocin-induced diabetic rats. The result figured statistical data that indicated a significant increase in serum insulin level and a decrease in the blood glucose, glycosylated hemoglobin levels, total cholesterol, and serum triglycerides. So it can be concluded that $C$. trigonus had a beneficial effect as an antidiabetic agent by reducing the elevated blood glucose level and lipid profile of STZ-induced-diabetic rats [53].

\subsubsection{Antiwrinkle activity.}

Lyophilized juice of $C$. sativus fruit was calculated its ascorbic acid content concerning the standard compound. The result presented that its ascorbic acid content was $3.5 \pm 0.23 \%$ w/w. It can be concluded that $C$. sativus lyophilized juice was a good source of ascorbic acid, so it had the potential to be an antiwrinkle agent for cosmetic products [42].

\subsubsection{Analgesic.}

The aqueous extract of $C$. sativus fruit was examined at 250 and $500 \mathrm{mg} / \mathrm{kg}$. The analgesic effect of aqueous extract of $C$. sativus fruit was compared with diclofenac sodium as the standard. Strong analgesic effects were shown. In mice, a dose of $500 \mathrm{mg} / \mathrm{kg}$ inhibited the acetic acid-induced writhing and increased the latency time in the hot-plate test. Flavonoids and tannins were discovered in an aqueous extract of $C$. sativus fruit. The presence of them was responsible for its analgesic effects [28].

Cucumis ficfolius crude methanolic root extract and solvent fractions have analgesic activity. $C$. ficfolius crude root extract and solvent fractions have been evaluated with acidinduced writhing, hot plate, and formalin-induced paw licking test. The result revealed that the crude extract had analgesic activity $(72.5 \%)$ to acetylsalicylic acid in the acetic acid writhing test. Both crude extract and solvent fractions exhibited significant prolongation of nociception reaction time in the hot plate test. In the formalin-induced paw licking test, crude methanolic extract and solvent fractions showed a significant reduction of mean lick time with maximum protection, $64 \%$ in the early phase and $83 \%$ in the late phase. From those three tests, it can be concluded that $C$. ficfolius had good analgesic activity [54].

\subsubsection{Ulcerative colitis.}

C. sativus showed a potential therapeutic effect in the amelioration of experimental ulcerative colitis in Wistar rats that were administered with acetic acid via intrarectal. The acetic acid in Wistar rats enhanced ulcer area, ulcer index, spleen weight, colon weight to length ratio, colonic MPO (myeloperoxidase), and hematological parameter. Pretreatment with $C$. sativus for 7 days showed significant effects in lowering ulcer area and ulcer index at 250 and $500 \mathrm{mg} / \mathrm{kg}$ in acetic acid-induced colitis [55]. 


\subsubsection{Osteoarthritis.}

One hundred twenty-two patients (56 males and 66 females) aged between 40 and 75 years and diagnosed with moderate knee osteoarthritis were included in this test. Sixty-one patients received $1350 \mathrm{mg}$ glucosamine-chondroitin drug twice daily, and the other patients received $10 \mathrm{mg} C$. sativus aqueous extract twice daily. The result showed that the Western Ontario Master Universities Osteoarthritis Index (WOMAC) score was decreased in C. sativus aqueous extract group by $22.44 \%$ on day 30 and $70.29 \%$ on day 180 , compared to $14.8 \%$ and $32.81 \%$ decrease in the glucosamine chondroitin group. C. sativus aqueous extract had no adverse effect on patients. So, $C$. sativus aqueous extract could be an effective moderate knee osteoarthritis pain reducer and can be potentially used in the management of knee pain, stiffness, and other physical functions related to osteoarthritis [56].

\subsubsection{Wound healing.}

The purified Cucumis protease from $C$. sativus showed primary and secondary hemostatic activities as it cleaves both fibrinogens as well as fibrin. The purified Cucumis protease from $C$. sativus also reduced Prothrombin Time (PT), Activated Partial Thromboplastin Time (aPTT), and recalcification time. Because of its hemostatic activity, purified Cucumis protease from $C$. sativus can be used as an active agent for wound healing [57].

\section{Conclusions}

After a thorough literature review, we found that Cucumis genus plants are rich in phytochemical compounds, cucurbitacins, phenolic compounds, vitamins, minerals, fatty acids, and essential oils. Cucumis genus plants have some pharmacological properties such as antimicrobial, antioxidant, anti-inflammatory, anticancer, antidiabetic, antiwrinkle, and analgesic agent. They also have some potential therapeutic effects for ulcerative colitis, osteoarthritis, and wound healing.

\section{Funding}

This research received no external funding.

\section{Acknowledgments}

The authors thankfully acknowledge to School of Pharmacy, Bandung Institute of Technology.

\section{Conflicts of Interest}

The authors declare no conflict of interest.

\section{References}

1. Ozuna, C.; León-Galván, M.F. Cucurbitaceae seed protein hydrolysates as a potential source of bioactive peptides with functional properties. Biomed Res Int 2017, 2017, 2121878, https://doi.org/10.1155/2017/2121878.

2. Kim, M.Y.; Kim, E.J.; Kim, Y.N.; Choi, C.; Lee, B.H. Comparison of the chemical compositions and nutritive values of various pumpkin (Cucurbitaceae) species and parts. Nutr Res Pract 2012, 6, 21 - 27, http://doi.org/10.4162/nrp.2012.6.1.21. 
3. Mukherjee, P.K.; Maity, N.; Nema, N.K.; Sarkar, B.K. Bioactive compounds from natural resources against skin aging. Phytomedicine 2011, 19, 64 - 73, https://doi.org/10.1016/j.phymed.2011.10.003.

4. Sebastian, P.; Schaefer, H.; Telford, I.R.; Renner, S.S. Cucumber (Cucumis sativus) and melon (Cucumis melo) have numerous wild relatives in Asia and Australia, and the sister species of melon is from Australia. Proc Natl Acad Sci USA 2010, 107, 14269 - 14273, https://doi.org/10.1073/pnas.1005338107.

5. Ramezani, M.; Rahmani, F.; Dehestani, A. Comparison between the effects of potassium phosphite and chitosan on changes in the concentration of Cucurbitacin E and on the antibacterial property of Cucumis sativus. BMC Compl Alternative Med 2017, 17, 1 - 6, https://doi.org/10.1186/s12906-017-1808-y.

6. Waziri, M.; Saleh, I.A. Proximate analysis and phytochemical screening of Psidium guajava (Guava) and Cucumis sativus (Cucumber) grown in Gashua Fadama area of Yobe state, Nigeria. Int Res J Pure Appl Chem 2015, 77 - 83, https://doi.org/10.9734/IRJPAC/2015/13775.

7. Rajasree, R.S.; Sibi, P.I.; Francis, F.; William, H. Phytochemicals of Cucurbitaceae family. Int J Pharmacogn Phytochem Res 2016, 8, 113 - 123.

8. Tuama, A.A.; Mohammed, A.A. Phytochemical screening and in vitro antibacterial and anticancer activities of the aqueous extract of Cucumis sativus. Saudi J Biol Sci 2019, 26, $600 \quad-604$, https://doi.org/10.1016/j.sjbs.2018.07.012.

9. Patel, S.; Rauf, A. Edible seeds from Cucurbitaceae family as potential functional foods: Immense promises, few concerns. Biomed Pharmacother 2017, 91, 330-337, https://doi.org/10.1016/j.biopha.2017.04.090.

10. Yuan, R.Q.; Qian, L.; Yun, W.J.; Cui, X.H.; Lv, G.X.; Tang, W.Q.; Cao, R.C.; Xu, H. Cucurbitacins extracted from Cucumis melo L. (CuEC) exert a hypotensive effect via regulating vascular tone. Hypertension 2019, 42, 1152 - 1161, https://doi.org/10.1038/s41440-019-0258-y.

11. Ezekaibeya, A.C.; Nnenna, A.O.; Kenechukwu, O.C. Proximate, phytochemical and vitamin compositions of Cucumis metuliferus (horned melon) rind. J Complement Altern Med Res 2020, 40 - 50.

12. Barber, N.A. Arbuscular mycorrhizal fungi are necessary for the induced response to herbivores by Cucumis sativus. J Plant Ecol 2013, 6, 171 - 176, https://doi.org/10.1093/jpe/rts026.

13. Kaushik, U.; Aeri, V.; Mir, S.R. Cucurbitacins-an insight into medicinal leads from nature. Pharmacogn Rev 2015, 9, 12, https://doi.org/10.4103/0973-7847.156314.

14. Shang, Y.; Ma, Y.; Zhou, Y.; Zhang, H.; Duan, L.; Chen, H.; Zeng, J.; Zhou, Q.; Wang, S.; Gu, W.; Liu, M. Biosynthesis, regulation, and domestication of bitterness in cucumber. Science 2014, 346, 1084 - 1088 , https://doi.org/10.1126/science.1259215.

15. Luo, F.; Li, Q.; Yu, L.; Wang, C.; Qi, H. High concentrations of CPPU promotes cucurbitacin B accumulation in melon (Cucumis melo var. makuwa Makino) fruit by inducing transcription factor CmBt. Plant Physiol Biochem 2020, 154, 770 - 781, https://doi.org/10.1016/j.plaphy.2020.05.033.

16. Dong, Y.; Lu, B.; Zhang, X.; Zhang, J.; Lai, L.; Li, D.; Wu, Y.; Song, Y.; Luo, J.; Pang, X.; Yi, Z. Cucurbitacin E, a tetracyclic triterpenes compound from Chinese medicine, inhibits tumor angiogenesis through VEGFR2-mediated Jak2-STAT3 signaling pathway. Carcinogenesis 2010, 31, 2097 - 2104 , https://doi.org/10.1093/carcin/bgq167.

17. Ge, W.; Chen, X.; Han, F.; Liu, Z.; Wang, T.; Wang, M.; Chen, Y.; Ding, Y.; Zhang, Q. Synthesis of Cucurbitacin B Derivatives as Potential Anti-Hepatocellular Carcinoma Agents. Molecules 2018, 23, 3345, https://doi.org/10.3390/molecules23123345.

18. Xu, X.; Tang, L.; Shan, H.F.; Wang, Z.Q.; Shan, W.G. Study on extraction of Cucurbitacin B from the pedicel of Cucumis melo L. by acid hydrolysis. Adv Mat Res 2013, 704, $61 \quad-\quad 65$, https://doi.org/10.4028/www.scientific.net/AMR.704.61.

19. Cai, Y.; Fang, X.; He, C.; Li, P.; Xiao, F.; Wang, Y.; Chen, M. Cucurbitacins: A systematic review of the phytochemistry and anticancer activity. Am J Chin Med 2015, 43, $1331 \quad-\quad 1350$, https://doi.org/10.1142/S0192415X15500755.

20. Haminiuk, C.W.; Maciel, G.M.; Plata-Oviedo, M.S.; Peralta, R.M. Phenolic compounds in fruits-an overview. Int J Food Sci Tech 2012, 47, 2023-2044, https://doi.org/10.1111/j.1365-2621.2012.03067.x.

21. Abu-Reidah, I.M.; Arráez-Román, D.; Quirantes-Piné, R.; Fernández-Arroyo, S.; Segura-Carretero, A.; Fernández-Gutiérrez, A. HPLC-ESI-Q-TOF-MS for a comprehensive characterization of bioactive phenolic compounds in cucumber whole fruit extract. Food Res Int 2012, 46, $108 \quad-\quad 117$, https://doi.org/10.1016/j.foodres.2011.11.026.

22. Silva, M.A.; Albuquerque, T.G.; Alves, R.C.; Oliveira, M.B.; Costa, H.S. Melon (Cucumis melo L.) byproducts: Potential food ingredients for novel functional foods?. Trends Food Sci Technol 2020, 98,181 189, https://doi.org/10.1016/j.tifs.2018.07.005. 
23. Ismail, H.I.; Chan, K.W.; Mariod, A.A.; Ismail, M. Phenolic content and antioxidant activity of cantaloupe (Cucumis melo) methanolic extracts. Food Chem 2010, 119, $643 \quad$ - 647, https://doi.org/10.1016/j.foodchem.2009.07.023.

24. Mallek-Ayadi, S.; Bahloul, N.; Kechaou, N. Characterization, phenolic compounds and functional properties of Cucumis melo L. peels. Food Chem 2017, 221, 1691 - 1697 , https://doi.org/10.1016/j.foodchem.2016.10.117.

25. Vella, F.M.; Cautela, D.; Laratta, B. Characterization of polyphenolic compounds in cantaloupe melon byproducts. Foods 2019, 8, 196, https://doi.org/10.3390/foods8060196.

26. Ganji, S.M.; Singh, H.; Friedman, M. Phenolic content and antioxidant activity of extracts of 12 melon (Cucumis melo) peel powders prepared from commercial melons. J Food Sci 2019, 84, 1943 - 1948 , https://doi.org/10.1111/1750-3841.14666.

27. Essien, A.D. Comparative studies of the phytochemistry, proximate analysis, mineral and vitamin compositions of the methanol leaf extracts of Cucumis sativus L. and Daucus carota L. IJPR 2016, 6, 282.

28. Kumar, D.; Kumar, S.; Singh, J.; Vashistha, B.D.; Singh, N. Free radical scavenging and analgesic activities of Cucumis sativus L. fruit extract. J Young Pharm 2010, 2, 365 - 368, https://doi.org/10.4103/09751483.71627.

29. Hashem, A.; Alqarawi, A.A.; Radhakrishnan, R.; Al-Arjani, A.B.; Aldehaish, H.A.; Egamberdieva, D.; AbdAllah, E.F. Arbuscular mycorrhizal fungi regulate the oxidative system, hormones and ionic equilibrium to trigger salt stress tolerance in Cucumis sativus L. Saudi J Biol Sci 2018, 25, 1102 - 1114, https://doi.org/10.1016/j.sjbs.2018.03.009.

30. Mallek-Ayadi, S.; Bahloul, N.; Kechaou, N. Chemical composition and bioactive compounds of Cucumis melo L. seeds: Potential source for new trends of plant oils. Process Saf Environ Prot 2018, 113, 68 - 77 , https://doi.org/10.1016/j.psep.2017.09.016.

31. Solval, K.M.; Sundararajan, S.; Alfaro, L.; Sathivel, S. Development of cantaloupe (Cucumis melo) juice powders using spray drying technology. LWT - Food Sci Technol 2012, 46, 287 - 293, https://doi.org/10.1016/j.lwt.2011.09.017.

32. Falodun, E.J.; Ogedegbe, S.A. Performance and quality of muskmelon (Cucumis melo L.) as influenced by crop spacing and rates of swine manure application. Not Sci Biol 2019, 11, 291 - 297, https://doi.org/10.15835/nsb11210431.

33. Gómez-García, R.; Campos, D.A.; Aguilar, C.N.; Madureira, A.R.; Pintado, M. Valorization of melon fruit (Cucumis melo L.) by-products: phytochemical and biofunctional properties with emphasis on recent trends and advances. Trends Food Sci Technol 2020, 99, 507 - 519, https://doi.org/10.1016/j.tifs.2020.03.033.

34. Rashid, U.; Rehman, H.A.; Hussain, I.; Ibrahim, M.; Haider, M.S. Muskmelon (Cucumis melo) seed oil: A potential non-food oil source for biodiesel production. Energy 2011, 36, 5632 - 5639, https://doi.org/10.1016/j.energy.2011.07.004.

35. Sotiroudis, G.; Melliou, E.; Sotiroudis, T.G.; Chinou, I. Chemical analysis, antioxidant and antimicrobial activity of three Greek cucumber (Cucumis sativus) cultivars. J Food Biochem 2010, 34, 61 - 78, https://doi.org/10.1111/j.1745-4514.2009.00296.x.

36. Tang, J.; Meng, X.; Liu, H.; Zhao, J.; Zhou, L.; Qiu, M.; Zhang, X.; Yu, Z.; Yang, F. Antimicrobial activity of sphingolipids isolated from the stems of cucumber (Cucumis sativus L.). Molecules 2010, 15, 9288 - 9297 , https://doi.org/10.3390/molecules15129288.

37. Al Akeel, R.; Mateen, A.; Alharbi, K.K.; Alyousef, A.A.; Al-Mandeel, H.M.; Syed, R. Purification and MIC analysis of antimicrobial proteins from Cucumis sativus L. seeds. BMC Complement Altern Med 2018, 18, 1 - 6, https://doi.org/10.1186/s12906-018-2176-y.

38. Netai, M.M.; Stephen, N.; Musekiwa, C. Synthesis of silver nanoparticles using wild Cucumis anguria: Characterization and antibacterial activity. Afr $J$ Biotechnol 2017, 16, 1911 - 1921, https://doi.org/10.5897/AJB2017.16076.

39. Ibrahim, S.; Al Haidari, R.; Mohamed, G.; Elkhayat, E.; Moustafa, M. Cucumol A: A cytotoxic triterpenoid from Cucumis melo seeds. Rev Bras Farmacogn 2016, 26, $701 \quad-\quad 704$, http://doi.org/10.1016/j.bjp.2016.03.012.

40. Ibrahim, S.R.; Mohamed, G.A. Cucumin S, a new phenylethyl chromone from Cucumis melo var. reticulatus seeds. Rev Bras Farmacogn 2015, 25, 462 - 464, https://doi.org/10.1016/j.bjp.2015.06.006.

41. Vishwakarma, V.K.; Gupta, J.K.; Upadhyay, P.K. Pharmacological importance of Cucumis melo L.: An overview. Asian J Pharm Clin Res 2017, 10, 8, http://dx.doi.org/10.22159/ajpcr.2017.v10i3.13849. 
42. Nema, N.K.; Maity, N.; Sarkar, B.; Mukherjee, P.K. Cucumis sativus fruitpotential antioxidant, antihyaluronidase, and anti-elastase agent. Arch Dermatol Res 2011, 303, $247 \quad$ - 252, https://doi.org/10.1007/s00403-010-1103-y.

43. Morais, D.R.; Rotta, E.M.; Sargi, S.C.; Schmidt, E.M.; Bonafe, E.G.; Eberlin, M.N.; Sawaya, A.C.; Visentainer, J.V. Antioxidant activity, phenolics and UPLC-ESI (-)-MS of extracts from different tropical fruits parts and processed peels. Food Res Int 2015, 77, $392 \quad-\quad 399$, https://doi.org/10.1016/j.foodres.2015.08.036.

44. Bonesi, M.; Saab, A.M.; Tenuta, M.C.; Leporini, M.; Saab, M.J.; Loizzo, M.R.; Tundis, R. Screening of traditional Lebanese medicinal plants as antioxidants and inhibitors of key enzymes linked to type 2 diabetes. Plant Biosyst 2020, 154, 656 - 662, https://doi.org/10.1080/11263504.2019.1674400.

45. Hashemi, Z.; Ebrahimzadeh, M.A.; Khalili, M. Sun protection factor, total phenol, flavonoid contents and antioxidant activity of medicinal plants from Iran. Trop J Pharm Res 2019, 18, 1443 - 1448, http://dx.doi.org/10.4314/tjpr.v18i7.11.

46. Nasrin, F.; Bulbul, I.J.; Aktar, F.; Rashid, M.A. Anti-inflammatory and antioxidant activities of Cucumis sativus leaves. Bangladesh Pharm J 2015, 18, 169 - 173, https://doi.org/10.3329/bpj.v18i2.24317.

47. Bernardini, C.; Zannoni, A.; Bertocchi, M.; Tubon, I.; Fernandez, M.; Forni, M. Water/ethanol extract of Cucumis sativus L. fruit attenuates lipopolysaccharide-induced inflammatory response in endothelial cells. BMC Complement Altern Med 2018, 18, 194, https://doi.org/10.1186/s12906-018-2254-1.

48. Trejo-Moreno, C.; Méndez-Martínez, M.; Zamilpa, A.; Jiménez-Ferrer, E.; Perez-Garcia, M.D.; MedinaCampos, O.N.; Pedraza-Chaverri, J.; Santana, M.A.; Esquivel-Guadarrama, F.R.; Castillo, A.; CervantesTorres, J. Cucumis sativus aqueous fraction inhibits angiotensin II-induced inflammation and oxidative stress in vitro. Nutrients 2018, 10, 276, https://doi.org/10.3390/nu10030276.

49. Nash, R.J.; Bartholomew, B.; Penkova, Y.B.; Rotondo, D.; Yamasaka, F.; Stafford, G.P.; Jenkinson, S.F.; Fleet, G.W. Iminosugar idoBR1 isolated from Cucumber Cucumis sativus reduces inflammatory activity. ACS Omega 2020, 5, 16263 - 16271, https://doi.org/10.1021/acsomega.0c02092.

50. Ezzat, S.M.; Raslan, M.; Salama, M.M.; Menze, E.T.; El Hawary, S.S. In vivo anti-inflammatory activity and UPLC-MS/MS profiling of the peels and pulps of Cucumis melo var. cantalupensis and Cucumis melo var. reticulatus. J Ethnopharmacol 2019, 237, 245 - 254, https://doi.org/10.1016/j.jep.2019.03.015.

51. Alsayari, A.; Kopel, L.; Ahmed, M.S.; Soliman, H.S.; Annadurai, S.; Halaweish, F.T. Isolation of anticancer constituents from Cucumis prophetarum var. prophetarum through bioassay-guided fractionation. BMC Complement Altern Med 2018, 18, 274, https://doi.org/10.1186/s12906-018-2295-5.

52. Dixit, Y.; Kar, A. Protective role of three vegetable peels in alloxan induced diabetes mellitus in male mice. Plant Foods Hum Nutr 2010, 65, 284 - 289, https://doi.org/10.1007/s11130-010-0175-3.

53. Salahuddin, M.D.; Jalalpure, S.S. Antidiabetic activity of aqueous fruit extract of Cucumis trigonus Roxb. in streptozotocin-induced-diabetic rats. $J \quad$ Ethnopharmacol $2010, \quad 127, \quad 565 \quad-\quad 567$, https://doi.org/10.1016/j.jep.2009.10.018.

54. Demsie, D.G.; Yimer, E.M.; Berhe, A.H.; Altaye, B.M.; Berhe, D.F. Anti-nociceptive and anti-inflammatory activities of crude root extract and solvent fractions of Cucumis ficifolius in mice model. J Pain Res 2019, 12, 1399, https://dx.doi.org/10.2147\%2FJPR.S193029.

55. Patil, M.V.; Kandhare, A.D.; Bhise, S.D. Effect of aqueous extract of Cucumis sativus Linn. fruit in ulcerative colitis in laboratory animals. Asian Pac J Trop Biomed 2012, 2, 962 - 969, https://doi.org/10.1016/S22211691(12)60344-X.

56. Nash, R.J.; Azantsa, B.K.; Sharp, H.; Shanmugham, V. Effectiveness of Cucumis sativus extract versus glucosamine-chondroitin in the management of moderate osteoarthritis: a randomized controlled trial. Clin Interv Aging 2018, 13, 2119, https://doi.org/10.2147/CIA.S173227.

57. Nafeesa, Z.; Shivalingu, B.R.; Neema, K.N.; Achar, R.R.; Venkatesh, B.K.; Hanchinal, V.; Priya, B.S.; Swamy, S.N. Procoagulant serine glycoprotease from Cucumis sativus L.: action on human fibrinogen and fibrin clot. Biotech 2017, 7, 96, https://doi.org/10.1007/s13205-017-0686-9. 